MEMÓRIA

\title{
Política de Ciência e Tecnologia no III PBDCT (1980/1985)
}

Sergio Salles Filho

Professor do Departamento de Política Científica e Tecnológica/Instituto de Geociências/UNICAMP

Neste número da Revista Brasileira de Inovação chegamos ao final desta série de três publicações que recuperam a memória de algumas das idéias fundamentais do planejamento de ciência e tecnologia no Brasil, expressas nos três Planos Básicos de Desenvolvimento Científico e Tecnológico (PBDCT).É espantosa, para os dias de hoje, a coerência e o alinhamento da política de C\&T de então com as políticas de desenvolvimento econômico, industrial e agrícola. Talvez pelo fato de estarmos há muito tempo sem planejamento neste País, ou no máximo com fragmentos de planejamento, aqui e acolá, sem coesão, os PBDCTs revelam uma fase em que havia planejamento integrado. Uma coisa não acontecia sem a outra, pelo menos no plano dos "Planos".

Tal qual o Primeiro e o Segundo PBDCTs, o Terceiro foi publicado como "detalhamento do tema especial 'Ciência e Tecnologia' do Capítulo VI do III Plano Nacional de Desenvolvimento". Aprovado na $18^{a}$ reunião do Conselho Científico e Tecnológico do CNPq, o III PBDCT foi publicado em 3 de setembro de 1980, em Decreto assinado pelo presidente João Baptista de Oliveira Figueiredo e pelo Ministro do Planejamento, Antonio Delfim Netto.' Valeria até 1985.

O II PBDCT foi assinado por 17 ministros. Aí uma das diferenças da força do planejamento (não da Pasta Ministerial, mas da ação de planejamento) dos Planos Nacionais de Desenvolvimento. A época do general Ernesto Geisel havia passado e iniciava-se a do General João Figueiredo. 
"O III PBDCT deverá servir de traço de união entre as açôes das diversas agências e órgãos de governo que operam na área de coordenação, fomento e execução das atividades de pesquisa e desenvolvimento e outras correlatas, sem descuidar da harmonização das diversas politicas de desenvolvimento econômico e social que interferem em seus objetivos."

Nas palavras do então presidente do CNPq, Dr. Lynaldo Cavalcanti de Albuquerque, este Plano diferia dos anteriores, pois se centrava mais em diretrizes que em programas, projetos e prioridades. Neste sentido, inaugurava-se um novo mecanismo: o Plano definiria linhas gerais e deveria ser completado por "um processo de seleção de programas e atividades prioritárias a serem implementadas nos diversos setores". Este processo daria origem a outra importante peça do planejamento científico e tecnológico no País, as Ações Programadas em Ciência e Tecnologia, com orçamento e revisão anuais.

$\mathrm{Na}$ verdade, o III PBDCT diferia dos anteriores também em seu foco: ciência mais que tecnologia, tecnologia mais que inovação. A prioridade bem expressa (mas não necessariamente executada) dos Planos anteriores que vinculava C\&T com desenvolvimento industrial e econômico não é tão explícita assim neste III Plano. Havia sim uma determinação voltada para a formação de recursos humanos, seja para a pesquisa científica, seja para a capacitação tecnológica naquilo que hoje se conhece como tecnologia industrial básica (metrologia, normalização, certificação, propriedade intelectual, informação tecnológica, engenharia de projetos etc.).

No capítulo 6, o Plano destaca:

"Para a articulação entre os centros de pesquisa e desenvolvimento e as empresas do setor industrial deve-se utilizar (...) o projeto de pesquisa e desenvolvimento contratado com a empresa cliente, e, quando necessário, com a participação de empresas de engenharia de projetos, visando à utilização prática dos resultados da pesquisa”.

A lógica era transferir o conhecimento técnico avançado dos centros de pesquisa industrial para as empresas nacionais. Por detrás, um espírito ofertista, mas já preocupado em juntar a pesquisa pública com a empresa, ainda que fosse 
para serviços técnicos especializados. Não por acaso, essa mesma lógica teve grande estímulo na Secretaria de Tecnologia Industrial do então Ministério da Indústria e Comércio.

Não se tratava mais de um Plano que unia, indissociavelmente, a C\&T à política de desenvolvimento econômico do País, dentre outras coisas porque a política de C\&T passava à esfera do CNPq, por meio do CCT (Conselho Científico e Tecnológico). A academia voltava a comandar a política científica e tecnológica do País. ${ }^{2}$ Talvez por isso o III PBDCT não fosse tão detalhado quanto às prioridades de política industrial e econômica como o foram os Planos anteriores.

Na prática, o que viria a valer como instrumento de definição de prioridades seriam as Ações Programadas do CNPq. Assunto suficiente para preencher esta sessão "Memória” da RBI por mais um ou dois números.

Assim, na opinião do autor desta introdução, o III PBDCT representa uma perda da capacidade de planejamento sistêmico. Não que se pudesse creditar aos Planos anteriores resultados expressivos de desenvolvimento tecnológico ligados ao desenvolvimento industrial. Na execução, os PBDCTs ficaram aquém de suas propostas, pelo menos no que diz respeito à criação de uma cultura da inovação. Não o fizemos nos anos 1970, quando essa intenção era a mais explícita possível. Com ainda menos razão o faríamos nos primeiros anos da década de 1980, quando a demonstração de vínculo entre C\&T e desenvolvimento assumiu uma retórica visivelmente artificial. No fundo, desgastava-se a própria capacidade de planejamento dos últimos anos do governo militar. Criamos, a partir de meados dos anos 1980, a cultura do cientista administrador público, que normalmente gasta seu mandato aprendendo a lidar com a máquina pública federal, com um olho em sua universidade e outro na ciência.

De certo, esta é uma visão pessimista, mas o fato é que voltamos, vejam vocês, "à briga estéril e anacrônica sobre a distinção de prioridades entre pesquisa básica, pesquisa aplicada e desenvolvimento experimental”. Neste meio tempo tivemos até ilustres cientistas ministros que não escondiam sua irritação com a idéia de planejamento de C\&T. Perdemos tempo, fomos e voltamos dando voltas atrás do próprio rabo. A segunda metade dos anos 1980 e a pri-

\footnotetext{
2 Não que tivesse deixado de fazê-lo nos anos 1970, mas sua autonomia se havia reduzido no Primeiro e no Segundo Planos. Agora, a academia era não apenas fortalecida, mas institucionalizada no comando da política no interior do CNPq.
} 
meira dos anos 1990, com o PADCT, ilustram bem essa situação. Fica aqui o convite para seguirmos no tempo: a análise das Ações Programadas e do PADCT são importantes para completar essa história.

Para reforçar o que dissemos acima, seguem-se alguns trechos do III PBDCT, selecionados nos seus pontos mais substantivos para leitura e releitura dos interessados. 


\section{Apresentação}

O III Plano Básico de Desenvolvimento Científico e Tecnológico (III PBDCT), representa um desdobramento do tema Ciência e Tecnologia do III PND. Como tal explicita a política do Governo para a área e orienta as ações a serem executadas no período 1980/85.

O III PBDCT deverá servir de traço de união entre as ações das diversas agências e órgãos de Governo que operam na área de coordenação, fomento e execução das atividades de pesquisa e desenvolvimento e outras correlatas, sem descuidar da harmonização das diversas políticas de desenvolvimento econômico e social que interferem em seus objetivos.

Centrado no Conselho Científico e Tecnológico (CCT) do CNPq, onde se fazem representar os Ministérios e órgãos de Governo envolvidos com Ciência e Tecnologia, a comunidade científica e técnica e a classe empresarial, o III PBDCT partiu de um documento preliminar elaborado pelo CNPq, e foi enriquecido com sugestôes dos membros do CCT e de outros setores da sociedade. O processo de discussão do Plano deu origem a linhas de ação que representam um detalhamento inicial de suas diretrizes. Essas linhas de ação, apresentadas em anexo, têm um caráter apenas indicativo, não esgotando, portanto, todas as ações que serão empreendidas no período $1980 / 85$.

O Plano foi elaborado na forma de um documento de diretrizes de política, definidas de modo participativo e que servirão para orientar as ações dos setores público e privado. Difere, portanto, do I e II PBDCT, que apresentavam as ações do governo sob a forma de programas, projetos e atividades prioritárias.

O processo de planejamento governamental não se esgota na elaboração de um plano. Pretende-se que o III PBDCT seja um roteiro flexível de atuação do Sistema Nacional de Desenvolvimento Científico e Tecnológico (SNDCT), possibilitando, por conseguinte, reajustes a situações emergentes.

Ao Plano se seguirá um processo de seleção de programas e atividades prioritárias a serem implementadas nos diversos setores. Tal processo, promovido e coordenado pelo CNPq, através do CCT, com a participação ativa de cientistas, técnicos, empresários e órgãos do SNDCT, dará origem à 
"Ação Programada em Ciência e Tecnologia" e seu respectivo orçamento-programa, revistos anualmente através de acompanhamentos e avaliaçôes físicofinanceiras.

Lynaldo Cavalcanti de Albuquerque

Presidente do CNPq 


\section{Capítulo 1}

\section{Evolução e Quadro Atual da Política de Ciência e Tecnologia}

$\mathrm{Na}$ última década, ocorreu no Brasil, significativo avanço das atividades de Ciência e Tecnologia. Todavia, esse avanço não foi acompanhado, na medida desejável, de transferência e absorção, pelos setores produtivos nacionais e outros segmentos da sociedade, das tecnologias desenvolvidas internamente ou adquiridas no exterior.

A descontinuidade do processo de consolidação de uma estrutura científica e tecnológica, a insuficiente articulação do SNDCT e a carência de recursos humanos qualificados na produção, no uso e difusão do conhecimento científico e tecnológico são alguns dos problemas que deverão ser equacionados e resolvidos no período de vigência do III PBDCT.

Embora a capacidade de produzir e inovar do SNDCT dependa tanto da sua expansão continuada como de seu nível de integração, ela fica, também, condicionada à existência de uma política científica e tecnológica, que dê contas das especificidades da área e, além disso, à necessária articulação e identificação com uma política global de desenvolvimento que assegure a sua utilização plena e continuada, ao longo do tempo.

O I PBDCT, que vigorou no período 1973/74, teve o mérito de focalizar a atenção de diferentes áreas de Governo e da sociedade em geral, em torno da importância da Ciência e da Tecnologia. Como conseqüência, promoveu a ampliação substancial dos recursos para a área, através do fortalecimento do Fundo Nacional de Desenvolvimento Científico e Tecnológico FNDCT - e de outros mecanismos financeiros, objetivando o reforço institucional da infra-estrutura de pesquisa e desenvolvimento, principalmente na área oficial.

Já o II PBDCT buscou, no período 1975/79, ampliar a oferta de Ciência e Tecnologia e criar condições para a estruturação do SNDCT, atribuindo ao CNPq a tarefa de coordenação geral. Da mesma forma, procurou-se reforçar a capacidade tecnológica da empresa nacional, encontrando-se este trabalho, ainda em fase de consolidação.

A política de desenvolvimento científico e tecnológico, expressa neste III PBDCT, objetiva uma crescente capacitação científica e uma maior auto- 
nomia tecnológica para o País. Esta política não se limitará ao período de vigência do Plano. Ela tem uma perspectiva de longo prazo.

A importância da Ciência e da Tecnologia deve-se ao seu valor estratégico tanto para atender à necessidade de elevação significativa do bem-estar material e social da população brasileira, como para aumentar o poder de negociação do País no cenário internacional. Em ambos aspectos, esta maior autonomia significa ampliar as condições de controle do processo de desenvolvimento nacional. A capacidade do País em superar as suas dificuldades internas e as oscilações da economia internacional, será tanto maior quanto maior for o domínio nacional do conhecimento científico e tecnológico, sobretudo em áreas estratégicas.

Diante do atual quadro econômico nacional, torna-se importante reorientar adequadamente os recursos disponíveis, com vistas ao aumento do rendimento dos investimentos, utilizando-se mais intensa e racionalmente a Ciência e Tecnologia, áreas em que os recursos devem ser ampliados, de forma a permitir ao País a possibilidade de identificar alternativas viáveis para a reorientação do processo de desenvolvimento.

Assim, no período de atuação deste III PBDCT, serão garantidas a consolidação e a continuidade de funcionamento das estruturas existentes dedicadas à pesquisa e à formação de recursos humanos. As atividades de Ciência e Tecnologia serão expandidas em setores estratégicos, de forma a assegurar a superação das dificuldades econômicas presentes, inclusive o equilíbrio do balanço de pagamentos especialmente no apoio à agricultura, a soluções para o problema energético e para o desenvolvimento social.

Cabe por fim, enfatizar que a consolidação e viabilização da política de Ciência e Tecnologia serão também garantidas através da continuidade e intensificação da articulação entre os diversos órgãos do SNDCT, assim definidos:

- as universidades e institutos científicos autônomos, contribuindo na formação de recursos humanos para a pesquisa e na geração, absorção e difusão do conhecimento científico e tecnológico;

- os centros de pesquisa e desenvolvimento, através da geração, domínio e difusão de conhecimentos tecnológicos para os diversos setores da atividade produtiva e da participação na formação dos recursos humanos; 
- as entidades governamentais, através do emprego de diversas modalidades de cooperação técnica e financeiras e da utilização do seu poder de compra de bens, serviços e tecnologias desenvolvidas no País;

- a empresa nacional, pública e privada, no desenvolvimento da demanda de conhecimentos e na geração, absorção e difusão de inovações tecnológicas. 


\section{Capítulo 2}

\section{A Política de Ciência e Tecnologia no Período 1980-1985}

A política de Ciência e Tecnologia continuará tendo por pressuposto a busca da melhoria das condições de vida da população e objetivará alcançar uma crescente capacitação científica e maior autonomia tecnológica.

A capacitação científica será alcançada pela qualidade, continuidade e expansão das atividades de pesquisa. Entende-se que estas têm valor em si mesmas por fazer parte integrante e essencial do desenvolvimento sociocultural do País, e como ambiência de formação de recursos humanos de alto nível, e fonte de conhecimentos para a criação de novas perspectivas tecnológicas de um dado setor.

A autonomia tecnológica define a capacidade de gerar e selecionar entre as opções disponíveis, a tecnologia mais adequada, além de promover a sua efetiva absorção e de privilegiar critérios socio-econômicos de longo prazo, na tomada destas decisões.

A Ciência e Tecnologia têm papel fundamental na resolução de problemas advindos do rápido processo de crescimento econômico brasileiro, devido ao seu relacionamento direto com o sistema produtivo. Dada a vantagem de se ter uma potencialidade técnica prontamente mobilizável para busca, adaptação ou consolidação dessas soluções, é conveniente dar um tratamento contínuo e de mais longo prazo às mesmas.

Nos últimos anos tem-se observado um decréscimo, em termos reais, dos recursos orçamentários das entidades executoras e financiadoras da área científico-tecnológica. Para garantir a continuidade e expansão das atividades de ciência e tecnologia, é política do Governo reforçar as dotações orçamentárias das entidades executoras, assegurando sua estabilidade financeira, e a das agências financiadoras, permitindo o apoio adequado às suas atividades de fomento.

\section{Capacitação Científica}

Para consolidar o processo de desenvolvimento científico e tecnológico, garantir-se-á a continuidade e a expansão da produção do conhecimento científico, envolvendo maior parcela da comunidade científica na definição das prioridades e programas investimentos em ciência. Tais prioridades deverão levar em conta o progresso científico, com especial atenção na formação e fixação de 
recursos humanos qualificados, na sustentação de trabalhos individuais e de programas de pesquisa conduzidos por equipes e instituições, na abertura de novas áreas consideradas importantes para o desenvolvimento científico brasileiro, e na progressiva incorporação dos conhecimentos científicos à vida econômica do País.

Serão ampliados os quadros de pesquisadores através da expansão da pósgraduação em setores e regiōes ainda carentes e da estabilização e melhoria de suas condições de trabalho. Procurar-se-á, ainda, cuidar da estruturação da carreira de pesquisador e do estabelecimento de mecanismos de acesso e remuneração atraentes.

O apoio à pesquisa e à formação de recursos humanos estará articulado com a política nacional de educação e formação de recursos humanos em geral, consideradas as circunstâncias regionais, de forma a possibilitar a um número crescente de pessoas, iniciar e concluir o processo de formação ou aperfeiçoamento nos diversos campos da ciência.

\section{Autonomia Tecnológica}

Como orientação prioritária, deve-se criar condições e mecanismos para geração interna de tecnologia. Para tanto, será estimulada a orientada a demanda do sistema produtivo nacional, e ampliada a geração e disseminação de tecnologias de origem local. Estas devem ser desenvolvidas levando em conta a disponibilidade de recursos naturais e adequação às condições socioeconômicas e culturais das diferentes regiōes do País.

A empresa é o agente de inserção e disseminação de inovações técnicas na economia. Assim, a empresa nacional, pública e privada, deve estar engajada no esforço de domínio da tecnologia utilizada, sobretudo no que lhe assegure a capacidade de decisão, a nível técnico e gerencial. As ações nesse sentido deverão levar em conta o porte da empresa e as peculiaridades do setor em que opera, devendo ser criados instrumentos que favoreçam a geração de tecnologia na própria empresa. Nos casos em que seja indispensável a aquisição de tecnologia do exterior, será incentivada maior articulação entre a empresa adquirente e as empresas de engenharia de projeto, os centros de pesquisa e desenvolvimento, as universidades e as instituições científicas isoladas, visando aumentar a capacidade de negociação e possibilitar a efetiva absorção da tecnologia adquirida. 
Os centros de pesquisa e desenvolvimento, constituem importante repertório de conhecimento técnico e desempenham papel relevante na difusão da tecnologia e na formação de recursos humanos para a área. É de fundamental importância a utilização de toda a capacidade instalada nesses centros, estabelecendo-se mecanismos de interação entre eles e outras instituições demandantes de conhecimentos. Dever-se-á também, fortalecer os centros de pesquisa e de desenvolvimento regionais, em consonância com as diretrizes de Governo, que preconizem a descentralização econômica do País.

Para efetivar a capacitação na área tecnológica, serão ainda apoiados a formação e aperfeiçoamento de recursos humanos necessários à geração, absorção, operação e transferência de tecnologia e à administração desse processo em seus diversos níveis, utilizando-se o sistema de ensino superior e, especialmente, os centros de pesquisa e desenvolvimento. Paralelamente, medidas complementares serão tomadas com o objetivo de sedimentar uma infra-estrutura de apoio ao desenvolvimento tecnológico. Assim, caberá fortalecer os sistemas de propriedade industrial, de metrologia, normalização e certificação de coleta e difusão de informação tecnológica, a capacitação em engenharia de projetos básicos e a produção nacional de instrumentos e insumos para a pesquisa.

Medidas serão tomadas, algumas de cunho indireto, destinadas a reduzir os riscos e os custos de desenvolvimento de tecnologia própria. Determinadas medidas serão articuladas com a política industrial e com a política fiscal e de formação de preços, enquanto outras utilizarão os mecanismos de apoio à pequena e média empresas. Outras, utilizarão o poder de compra das empresas estatais e a demanda de organismos governamentais responsáveis pela execução de programas de interesse social, como: saúde, nutrição, educação, saneamento e habitação. 


\section{Capítulo 3}

\section{Instrumentos de Ação}

Com o objetivo de implementar as diretrizes estabelecidas no III PBDCT, serão mobilizados e reorientados os instrumentos de coordenação e planejamento no SNDCT e os instrumentos financeiros, fiscais e creditícios em vigor, sem prejuízo da necessidade de criação de novos mecanismos. Dada a amplitude de seu alcance, e principalmente de suas características multissetoriais, tais instrumentos serão operados em ação coordenada e articulada.

\section{Coordenação das Atividades}

A estruturação do SNDCT deverá estar concluída no período de vigência deste Plano, de forma a alcançar a integração dos diversos órgãos e ações relacionadas com Ciência e Tecnologia, sob a coordenação do Conselho Científico e Tecnológico (CCT) do CNPq.

Para tanto, serão adotadas medidas no sentido de:

- consolidar o CCT como órgão de definição de política, de fixação de diretrizes e prioridades para a área de Ciência e Tecnologia, e também da coordenação, acompanhamento e avaliação da execução, e de sua compatibilização com as políticas e objetivos de Governo;

- articular o CCT com outros órgãos colegiados que inflem na política científica e tecnológica, encaminhando-lhe resoluções e submetendolhe propostas;

- incentivar a criação de órgãos e sistemas federais, regionais e estaduais de Ciência e Tecnologia, articulados com o SNDCT, e de programas ou fundaçôes estaduais voltadas ao estímulo do desenvolvimento científico e tecnológico.

\section{Planejamento de Ciência e Tecnologia}

O planejamento de Ciência e Tecnologia deverá se dar de forma contínua, cabendo ao CCT papel central no processo, contando com a participação efetiva dos órgãos componentes do SNDCT.

Os principais instrumentos de planejamento serão: 
- o Plano Básico de Desenvolvimento Científico e Tecnológico (PBDCT), que explicita as diretrizes de política e os setores prioritários de desenvolvimento;

- a Ação Programada em Ciência e Tecnologia, atualizada anualmente através do acompanhamento e avaliação do PBDCT, que representará o seu desdobramento em termos de programas e atividades, contendo um orçamento-programa.

\section{Informação em Ciência e Tecnologia}

O funcionamento ativo e integrado dos canais de comunicações da informação em Ciência e Tecnologia é essencial para o desenvolvimento científico e tecnológico do País, fornecendo as bases para o seu planejamento e acompanhamento.

É necessário sensibilizar a consciência nacional para a importância do uso da informação em Ciência e Tecnologia, objetivando o aperfeiçoamento de mecanismos de acesso, armazenamento e divulgação dessa informação. Necessário se faz, também, a formação e o treinamento de recursos humanos de alto nível técnico, no tratamento e na utilização da informação, devido a característica multidisciplinar do setor.

Serão incentivadas a documentação e sistematização da geração de informação científica e tecnológica nos agentes executores, a construção de sistemas de informação que interconectem as entidades públicas e privadas envolvidas, a coleta e a disseminação de informação científica e tecnológica estrangeira, quer através da ampliação de convênios internacionais, quer por convênios com empresas especializadas nesta área de informação, e as iniciativas voltadas para o efetivo funcionamento do Banco de Patentes.

Por outro lado, a crescente demanda por serviços de consulta a base de dados bibliográficos, disponíveis no exterior, vem incentivando empresas estrangeiras a oferecer seus serviços diretamente no País. A experiência de outros países recomenda o estabelecimento de uma legislação específica para controle deste tipo de serviço.

Assim, está prevista a implementação de uma política no sentido de atender às necessidades de informação em Ciência e Tecnologia do País, considerando sua peculiaridade e levando em conta que os recursos são escassos, 
e, portanto, precisam ser administrados racionalmente e com visão de conjunto. Isto requer o fortalecimento do Instituto Brasileiro de Informação em Ciência e Tecnologia (IBICT), do CNPq, como órgão central com condições institucionais e materiais para desempenhar funções de coordenação, descentralizada, das atividades de informação em Ciência e Tecnologia no País.

\section{Financiamento a Ciência e Tecnologia}

Será mantida a ação descentralizada das agências e fontes de financiamento, promovendo-se sua melhor articulação e maior coordenação.

Sob a coordenação do CCT serão tomadas as seguintes medidas:

- assessoramento na elaboração de um Orçamento de Ciência e Tecnologia, em articulação com o Sistema Federal de Programação e Orçamento, detalhado ao nível setorial, envolvendo as principais fontes de recursos federais e que será acompanhado e divulgado anualmente;

- explicitação e divulgação das dotações do Orçamento da União para Ciência e Tecnologia, devendo evoluir tais trabalhos, no sentido de participação do CCT no dimensionamento dos recursos destinados à área;

- estímulo à ampliação da participação dos Governos estaduais e empresas privadas no financiamento da atividade científica e tecnológica, de modo a complementar os recursos da área federal.

\section{Instrumentos Normativos, Fiscais e Creditícios}

O Sistema Nacional de Metrologia, Normalização e Qualidade Industrial e a área de Propriedade Industrial serão aperfeiçoados para garantir um crescimento mais regulado e harmônico da ciência e tecnologia.

Os sistemas fiscal e creditício serão objeto de estudos, de modo a utilizálos como instrumentos efetivos de estímulo à realização de atividades de pesquisa e desenvolvimento, pelas empresas, seja diretamente, seja através de subcontratação no País.

A sistemática de concessão de financiamento à empresa nacional no setor será aperfeiçoado visando a: dar maior racionalidade econômica ao elenco de subsídios; considerar as condiçôes de risco inerente às atividades de pesquisa e desenvolvimento; e ampliar a utilização de modalidades de partici- 
pação no risco da pesquisa, especialmente no caso da pequena e média empresas, em ramos específicos da produção.

\section{Cooperação Internacional}

A cooperação internacional em Ciência e Tecnologia deverá ser utilizada, primordialmente, como um instrumento subsidiário da execução deste III PBDCT.

O objetivo-síntese do Governo, através da ação do SNDCT, é aumentar o grau de autonomia científica e tecnológica, definida como a maior capacidade para gerar soluções próprias e selecionar tecnologias exógenas a serem transferidas.

A cooperação com países desenvolvidos deve contribuir especialmente para o fortalecimento da nossa estrutura científico-tecnológica. Já com países em desenvolvimento, deve buscar a solução dos problemas do desenvolvimento econômico e social, dentro do espírito da cooperação horizontal.

A cooperação internacional científica e tecnológica se processará através de uma ação integrada entre os diversos órgãos governamentais brasileiros, responsáveis pela elaboração e implementação das diretrizes de política no setor. 


\section{Capítulo 4}

\section{Desenvolvimento Científico e Formação de Recursos Humanos}

O fortalecimento e ampliação do domínio do conhecimento científico constitui uma das prioridades do III PND. Para tal, é importante identificar alguns dos principais problemas que afetam, em diferentes níveis, o processo de produção científica no Brasil.

Um dos obstáculos mais sérios diz respeito à instabilidade institucional e financeira, que limitam a continuidade dos programas de formação de recursos humanos e sua fixação nas instituiçôes. A estabilidade desejada nas universidades, nos institutos científicos isolados e nos centros de pesquisa e desenvolvimento pressupõe salários adequados para pesquisadores e pessoal técnico, infraestrutura técnico-administrativa compatível com a atividade de pesquisa, bem como laboratórios satisfatoriamente aparelhados e bibliotecas atualizadas. Atualmente, entretanto, a maior parte das pesquisas desenvolvidas nessas instituições é mantida com recursos extra-orçamentários, com conseqüente instabilidade de suas atividades.

No que se refere à formação de recursos humanos, a ampliação dos quadros para as atividades de pesquisa e desenvolvimento apresenta desafios de duas ordens. A primeira reside no mecanismo de formação e aperfeiçoamento de pesquisadores, enquanto que a segunda localiza-se na criação de condições adequadas ao trabalho de pesquisa.

A formação de pesquisadores está a cargo do sistema de pós-graduação, operado principalmente pela universidade, com importante contribuição de institutos científicos autônomos. Este sistema merece uma reavaliação para que não se comprometa a qualidade da formação de docentes-pesquisadores ou da produção científica. Em algumas áreas, a pós-graduação veio apenas suprir as deficiências da graduação, desvirtuando seus propósitos iniciais, a saber, a formação de docentes, pesquisadores e pessoal técnico de alto nível. Portanto, é necessário que a pós-graduação cumpra o seu objetivo fundamental, não ficando apenas no preenchimento das deficiências da graduação, atualização de conhecimentos ou consolidação de cargos na carreira universitária. Também a participação dos centros de pesquisa e desenvolvimento na formação desse pessoal deve ser mais explorada. 
Apesar da expansão quantitativa da pós-graduação, o número de pesquisadores qualificados é ainda insuficiente na maior parte das áreas do conhecimento, constituindo-se num ponto de estrangulamento primário para o desenvolvimento científico e tecnológico.

A carência de pessoal técnico de apoio constitui outra restrição ao desenvolvimento da pesquisa, seja pela pouca atenção dada à formação e ao treinamento do mesmo, seja pelas dificuldades de sua retenção nos órgãos de pesquisa.

Quanto às condições de trabalho dos pesquisadores encontram-se problemas no âmbito das universidades e das instituições de pesquisa e desenvolvimento, tais como: pouca flexibilidade na tomada de decisões e na gerência de recursos, fraco intercâmbio de pesquisadores, sobrecarga com outras atividades em detrimento da pesquisa e desatualização de bibliotecas e laboratórios.

Além disso, a interrelação entre a comunidade científica e outros setores da sociedade brasileira apresenta alguns problemas específicos. Freqüentemente, a comunidade científica não é chamada a participar da discussão sobre questôes de interesse geral, subestimando-se as informações e conhecimentos que os cientistas, as academias e sociedades científicas podem oferecer.

Visando ao aprimoramento da formação de recursos humanos e das atividades de pesquisa e desenvolvimento no País, ficam estabelecidas as seguintes diretrizes:

- Financiamento. Apoiar os grupos de pesquisa com significativa produção científica e tecnológica e os grupos emergentes com reconhecida potencialidade, provendo recursos orçamentários adequados ao desempenho de suas atividades e assegurando a efetiva coexistência da pesquisa, pós-graduação, graduação e extensão. Esse apoio será estendido a programas de iniciação científica, formação e aperfeiçoamento de pessoal auxiliar para pesquisa, suprimento e manutenção da infra-estrutura física e material necessária à pesquisa.

- Planejamento e Avaliação. Estimular o envolvimento dos pesquisadores na definição das diretrizes e prioridades da política científica e tecnológica para planejamento e estabelecimento de critérios, prazos e padróes de avaliação flexíveis e diferenciados, para atender as peculiaridades próprias das diversas áreas de conhecimento e regiōes do País, incrementando a prática de auto-avaliação, dentro da própria comunidade científico-tecnológica. 
- Regionalização. Estimular o desenvolvimento de programas e linhas de pesquisa que atendam as especificidades regionais do País, com aportes financeiros adequados para garantir autonomia de atuação a níveis regionais e transferência efetiva dos resultados para a comunidade.

- Aperfeiçoamento de Recursos Humanos. Promover a estabilidade e aperfeiçoamento contínuo dos quadros docentes e de pesquisadores, estimulando o regime de tempo integral, a criação das carreiras do pesquisador e de técnicos de níveis superior e médio, a integração efetiva do ensino com a pesquisa, a introdução da licença sabática e o intercâmbio de elementos entre as diversas instituições e regiōes do País. Paralelamente, será apoiada a expansão dos custos de especialização, atendendo as necessidades e características do mercado de trabalho e intensificada a participação dos centros de pesquisa e desenvolvimento na preparação de recursos humanos.

- Utilização da Infra-Estrutura. Estimular a produção nacional de componentes e produtos, a criação dos centros para aquisição e estocagem de suprimentos, o remanejamento de equipamentos entre instituiçóes de pesquisa, e a importação de produtos imprescindíveis à continuidade dos projetos de pesquisa, para melhorar a utilização da infra-estrutura física, ao lado do suprimento e manutenção dos equipamentos didáticocientíficos.

- Circulação de Informações. Dinamizar a circulação de informações, pela organização de sistemas de bibliotecas setoriais, estímulo à edição de livros e periódicos, apoio às academias e sociedades científicas, e promoções de diversas naturezas para divulgação e intercâmbio de informações técnicocientíficas. 


\section{Capítulo 5}

\section{Ciência e Tecnologia nos Setores Prioritários do III PND}

O III PND reconhece a necessidade de se alterar uma situação de dependência do Brasil em relação a países mais desenvolvidos, acentuadamente no campo da tecnologia. Nos setores prioritários do mesmo - energia, agricultura e desenvolvimento social - a busca de maior capacitação científica e da redução do grau de dependência tecnológica se traduzem em diretrizes de política orientadas para a diminuição da necessidade do País quanto à importação de insumos energéticos e para uma crescente capacidade de selecionar adequadamente tecnologias dentre as opçôes disponíveis, de promover a sua efetiva absorção e de gerar soluções próprias, em resposta às diversidades regionais da realidade brasileira.

Neste esforço é de fundamental importância a atuação dos centros de pesquisa e desenvolvimento já existentes, de forma a aproveitar e reforçar a sua capacitação, bem como estimular a demanda de soluções adequadas às necessidades sócio-econômicas e culturais do País, inclusive pela orientação dos investimentos governamentais e do poder de compra das empresas públicas.

Definidos os aspectos fundamentais da política de Ciência e Tecnologia e suas principais diretrizes - tanto no que diz respeito ao desenvolvimento científico como à capacidade de geração e absorção de tecnologia - cabe identificar as prioridades setoriais e as açôes pertinentes ao campo científico e tecnológico a serem implantadas. Embora abordados por tópicos, deve-se ter claro a interação dos diferentes níveis dos problemas, cuja solução exigirá análises multidisciplinares e decisões intersetoriais.

\section{Energia}

Dada a gravidade do problema energético, entende o Governo ser conveniente um esforço amplo e generalizado no que concerne à pesquisa e ao desenvolvimento tecnológico, complementado por estudos técnico-econômicos sobre fontes, formas, usos e poupança de energia, buscando-se respostas rápidas e eficientes para a redução progressiva das importações de energia e de tecnologia nesse campo. No caso brasileiro, a questão assume feição particularmente grave quanto a combustíveis derivados do petróleo. Serão mobilizados os recursos da 
Ciência e da Tecnologia para apoiar a atividade de prospecção de petróleo em território nacional, assim como para a pesquisa de fontes alternativas de energia. Esforço especial será dedicado aos produtos derivados de biomassa e carvão mineral, e à tecnologia para seu uso eficiente de modo a produzir economias apreciáveis de petróleo.

A poupança e a racionalização do uso da energia terão alta prioridade, o que demandará pesquisas e estudos em diversas áreas entre os quais os voltados à substituição de fontes de energia na indústria e no setor de transportes, bem como a difusão de métodos de poupança, como ênfase na assistência técnica, por parte do poder público, às empresas de pequeno e médio portes.

Na geração de energia hidrelétrica, o potencial disponível é amplo, oferecendo campo para um programa abrangente de desenvolvimento científico e tecnológico na transmissão a grandes distâncias, bem como em outras tecnologias de aproveitamento de recursos hídricos, até o presente considerados secundários para a geração de eletricidade. $\mathrm{Na}$ área termelétrica, terão destaque as pesquisas de aproveitamento do carvão mineral brasileiro. Ênfase também será dada à liquefação e gaseificação (inclusive in situ, como é também o caso do xisto) do carvão mineral. A energia nuclear continuará a ter ênfase visando a maior capacitação técnica e absorção da tecnologia dos reatores, fabricação de componentes, ciclo de combustível, com destaque para o enriquecimento e o reprocessamento.

O Programa Nacional do Álcool deverá receber o suporte tecnológico adequado, tanto para melhoria da eficiência do processo de produção do etanol, como para o aproveitamento do mesmo e de seus subprodutos.

Outras fontes de energia, solar e eólica, por exemplo, carecem de medidas bem estruturadas para o seu aproveitamento em escala, embora as tecnologias respectivas já sejam bem dominadas por grupos nacionais naquilo que diz respeito aos usos mais comuns. Neste aproveitamento, um dos aspectos mais importantes é a integração destas novas fontes no panorama energético do País.

\section{Agropecuária}

A prioridade concedida à agropecuária pelo III PND implica em esforços na área de ciência e tecnologia no sentido de consolidar os conhecimentos e transferi-los ao produtor, através da extensão rural, bem como de inovar as 
tecnologias visando ao aumento da produção e da produtividade. Esses esforços serão acompanhados por mudanças institucionais e inversões de capital, de forma a assegurar uma melhor utilização dos fatores de produção e maior integração entre agricultura e indústria.

Nesse sentido, a definição de diretrizes de política científica e tecnológica para a agropecuária, que devem adequar as ações setoriais com as prioridades do desenvolvimento nacional, implica, necessariamente, no acionamento e na utilização, simultânea e efetiva, dos instrumentos da política econômica, tais como política fundiária, crédito rural, preços mínimos compensadores, seguro rural, os quais se configuram indispensáveis à compatibilização dos esforços de pesquisa e à possibilidade de transferência e absorção de tecnologia pelo produtor.

Os estudos e pesquisas no setor terão como meta principal a expansão da produção vegetal, florestal e pesqueira e a melhoria da produtividade, de forma a contemplar, prioritariamente o equilíbrio entre a oferta e a demanda de alimentos e matérias-primas, bem como a formação de excedentes exportáveis. Ademais, o impacto da geração e difusão de novos conhecimentos sobre o aumento da produtividade e redução dos custos de produção poderão ter efeitos positivos sobre a melhoria das condições de vida da população rural, sobretudo através de uma adequada utilização do potencial produtivo dos pequenos e médios produtores, favorecendo, desta maneira, a elevação de sua renda real. Nesse sentido, pretender-se-á reduzir o distanciamento tecnológico existente no setor rural, desenvolvendo-se tecnologias acessíveis aos pequenos produtores, que sejam, a um só tempo, alternativas viáveis aos padrões tecnológicos próprios das grandes culturas e às técnicas que esses pequenos produtores dispóem nas suas atividades.

Paralelamente, esforços serão concentrados na busca de alternativas viáveis no que concerne às matérias-primas para a produção de álcool etílico e outros combustíveis, e aos insumos para a indústria química, visando a incrementar a exploração econômica de culturas tradicionais ou novas, com alta potencialidade para sua produção, cuidando para que não ocorram efeitos negativos sobre as áreas de lavouras de alimentos decorrentes de eventuais substituições de cultivos ou desvios de produtos básicos da alimentação popular para a produção de álcool. 


\section{Educação e Cultura}

A educação e a cultura constituem partes integrantes e fundamentais do processo de desenvolvimento, e devem ser entendidas nas suas dimensões mais amplas da conquista da liberdade, da criatividade e da cidadania. Por isso devem ser vistas no quadro das questôes socioeconômicas e políticas do País.

No que diz respeito ao conhecimento sobre a problemática da educação, os esforços da pesquisa concentrar-se-ão na criação, elaboração e transferência dos conhecimentos e métodos que venham contribuir para a adequação da rede escolar de $1^{\circ}$ e $2^{\circ}$ graus às necessidades do País e na melhoria qualitativa do sistema universitário, inclusive da pós-graduação. Terá prioridade a educação nas periferias urbanas e no meio rural, onde as deficiências se apresentam em maior grau, em todos os níveis, ressaltando-se as necessidades de alfabetização.

Serão pesquisados e aperfeiçoados métodos e instrumentos não-convencionais de treinamento e educação que possam tornar acessível, em escala, o aperfeiçoamento profissional. Também será estimulado o desenvolvimento de meios que ajudem à formação do espírito de pesquisa, sobretudo nos mais jovens.

Será, ainda, promovida a pesquisa para adequação do sistema educacional, em todos os seus níveis, às especifidades estruturais e regionais do País, tornando a educação um instrumento positivo na busca, pela população, de soluçôes para os seus próprios problemas e na participação mais ativa na discussão e no equacionamento das grandes questôes nacionais.

A cultura é concebida como ação e processo de produção intelectual que se nutre do passado para construir o futuro. Neste sentido, especial atenção será conferida aos esforços de preservação da memória cultural, histórica e científica visando não só recuperar o passado, como fornecer elementos de compreensão do presente. É também necessário trazer esta memória ao pesquisador, ao educador e à população em geral, transformando os museus e centros de referência em núcleos dinâmicos de preservação, criação e difusão de conhecimentos.

\section{Saúde e Nutrição}

A multiplicidade institucional representa uma das mais marcantes características do setor de saúde, acarreta a superposição de órgãos e programas, paralelamente ao esvaziamento de áreas prioritárias, como no caso das medidas de 
prevenção e saúde pública. Por outro lado, a organização dos serviços de atendimento médico, em termos de um complexo médico-industrial, tem determinado a sua estruturação em níveis de especialização e consumo sofisticados, não compatíveis com as reais necessidades e possibilidades da população. Assim é que os índices de mortalidade e morbidade ainda atingem níveis inaceitáveis, tendo em vista o estágio atual de desenvolvimento do País. Os dados sobre mortalidade infantil, desnutrição e suas conseqüências sobre doenças transmissíveis e outros, atestam ainda precárias condições de saúde das camadas populacionais de baixa renda, principalmente aquelas localizadas no meio rural ou nos bairros periféricos dos centros urbanos.

Deverão, portanto, ser atendidos os aspectos que se referem às ações de alcance individual ligadas à assistência médica integral no âmbito da prevenção, tratamento e reabilitação, bem como as ações de alcance coletivo e multidisciplinar, que constituem a saúde pública.

A questão de nutrição não se restringe tão-somente à oferta de alimentos, mas também aos fatores de emprego e renda, que vão determinar o perfil do estado nutricional. Assim sendo, a problemática nutricional articula variáveis sociais e biológicas, devendo por conseguinte, ser abordada em suas diferentes dimensões: econômicas, sociológicas, biológicas e culturais, entre outras.

Aqui, o principal objetivo da política científica e tecnológica será o de reforçar as medidas governamentais de extensão e melhoria de serviços de saúde pública. Isto poderá ser alcançado se as medidas de ação preventiva de natureza coletiva obtiverem a mesma prioridade que as medidas terapêuticas, de alcance individual, vêm obtendo até o momento.

Gastos crescentes no setor, sem reflexos positivos no nível de saúde, constituem um paradoxo apenas aparente, já que o grau de higidez de uma comunidade depende menos da amplitude ou sofisticação dos serviços médicos disponíveis do que de medidas preventivas mais amplas. Tais medidas diriam respeito, prioritariamente, a políticas sociais concernentes a emprego, salário, produção e comercialização de alimentos, habitação, saneamento e educação, que se refletem, sem dúvida, no nível de saúde da população.

A capacitação nacional em Ciência e Tecnologia, na área de saúde, será orientada no sentido de se atingir um grau de autonomia que possibilite, pela comunidade científica e pelo parque industrial nacional, a geração de tecnologias 
próprias e a efetiva absorção e adequação das tecnologias importadas, necessárias à produção dos insumos essenciais à saúde da população, bem como a normalização e controle de qualidade de insumos e produtos de interesse para a saúde, como meio de se reduzir a dependência a fontes externas de tecnologia e matérias-primas.

Será também, dada ênfase especial à formação de recursos humanos em cursos de graduação, nas áreas de saúde e nutrição, adequadas às reais necessidades destes setores, objetivando atender, localmente, as demandas da população, assim como cursos de medicina do trabalho, criação e aprimoramento de cursos de pós-graduação e formação de pesquisadores, principalmente os ligados à epidemiologia e saúde pública, nutrição, farmacologia e tecnologia de alimentos.

\section{Assistência Social}

$\mathrm{O}$ acesso às condições dignas de trabalho e remuneração constitui um dos principais fatores de valorização do homem. Para isso deverão ser buscados conhecimentos e soluçóes para a geração de novos empregos e melhoria da organização produtiva, complementado pelos serviços previdenciários e assistenciais.

Os esforços de Ciência e Tecnologia voltados para a assistência social visam, primordialmente, gerar um conhecimento amplo e concreto sobre a população não atendida pelo sistema de previdência, suas condições de vida e as causas imediatas de sua situação peculiar, seja por deficiência (físicas ou mentais), seja por decorrência de situações transitórias (migrações, calamidades e outras). Ao mesmo tempo, pretenderá contribuir para a melhoria técnica e organizacional das diferentes modalidades de atendimento, sejam elas previdenciárias ou não. No que diz respeito ao tratamento de portadores de deficiências físicas, a ciência e a tecnologia modernas possibilitarão um aumento de eficiência no esforço de desenvolvimento e recuperação.

Parcela significativa de apoio se destinará à procura e oferta de subsídios para a estruturação de novos mecanismos assistenciais e para a agilização dos existentes, principalmente aqueles que implicam no envolvimento direto e ativo da comunidade e no aumento da capacidade desta de cooperar na solução e prevenção de seus problemas. 


\section{Habitação e Saneamento}

O esforço desenvolvido pelo Governo na área de habitação está voltado para a redução do deficit habitacional. Além da edificação em si, a orientação governamental é de considerar como prioritárias as aspirações da população em termos de segurança sanitária, conforto, funcionalidade, adequação ambiental, localização espacial e equipamentos de infra-estrutura, a um custo acessível ao usuário e à coletividade.

As pesquisas e estudos no setor serão articulados por um planejamento urbano-rural integrado, que facilite a reorientação da indústria de construção e de materiais no sentido da melhor utilização dos fatores de produção, localmente abundantes, da padronização e produção seriada de materiais de construção, que vise a atingir faixas da população de baixa renda.

Assim, serão destacadas as ações que promovam a utilização, em larga escala, de tecnologias adequadas, que recorram a recursos humanos e materiais, localmente disponíveis, utilizem menos energia e envolvam as indústrias de pequeno porte. Ao mesmo tempo, será incentivado o fortalecimento dos centros de pesquisa regionais, reforçando estudos sobre a organização espacial do habitat residencial, pesquisas sobre materiais e processos construtivos e formação de recursos humanos.

Quanto ao saneamento básico, cuja situação no País ainda é precária daí a consideração global do problema, não só do ponto de vista setorial como espacial - há de se exigir o desenvolvimento de tecnologia própria e adequação de tecnologia importada, além da ampla qualificação de recursos humanos para pesquisa, de modo a se encontrar soluções mais simples, funcionais, eficazes e de menor custo, consideradas as características socioeconômicas e culturais da população.

Nesse sentido, serão apoiadas pesquisas que visem a compatibilizar as ações dos vários ministérios envolvidos nesta questão. Serão também reforçados ou criados canais específicos de demanda e incorporação dos resultados das pesquisas, incentivando, ao mesmo tempo, aquelas que busquem simplicidade, eficácia, menor custo e regionalização das soluções adotadas e apoiadas num amplo programa de formação de recursos humanos para pesquisa na área. 